\title{
Arquitectura cristiana y liturgia: reflexiones en torno a la interpretación funcional de los espacios
}

\author{
Cristina Godoy Fernandez *
}

El interés por la interpretación de la funcionalidad litúrgica de los distintos ámbitos de los primeros edificios de culto cristiano nace ya con la misma arqueología cristiana, cuando, en el siglo pasado, de la mano de Giuseppe Mardi y Giovanni Battista de Rossi, empezaron a exhumarse y a restaurarse los primeros restos de los antiguos templos cristianos '.

El decurso de esta joven ciencia en decenios posteriores llevó a una proliferación de los descubrimientos en todas las áreas del antiguo orbe cristiano. Hay que reconocer en este auge la importancia del papel jugado por la Iglesia Romana, tanto en la realización como en el mecenazgo de numerosas excavaciones arqueológicas. Cénit de esta propiciación eclesiástica a la arqueologia cristiana es la creación del Istituto Pontificio di Archeologia Cristiana cuyo magisterio ha irradiado durante generaciones en la formación de los mejores especialistas.

Esta predisposición de la Iglesia no se cerró únicamente en la arqueología cristiana, sino que se manifestó, de forma general, en el de-

* Universidad de Barcelona. Departamento de Arqueología Cristiana

Hay que destacar la obra fundamental de G. B. DE Rossi. La Roma sotterranea cristiana. Roma, 1864-1877, que revela el descubrimiento de las catacumbas y las restauraciones de los cubicula adecuados para el culto Cfr. tambien. P. TESTINI, Le catecombe e gli antichi cimiteri cristiani in Roma. Bolonia 1966: Id. Archeologia Cristiana, Bari 1980. 
sarrollo de las ciencias del cristianismo antiguo. Este hecho hubiera podido propiciar una estrecha colaboración interdisciplinar, pero, desgraciadamente, el distinto desenvolvimiento de estas ciencias llevaron por caminos bien diferentes a la arqueología - en su estudio por los restos materiales - de las disciplinas basadas en la interpretación de los textos escritos, como la patrística, la liturgia y la canonistica, disociación que, por otra parte, también se ha dejado sentir entre la arqueologia y la historia antigua. Con el tiempo, la arqueología cristiana - a diferencia del resto de las ciencias del cristianismo antiguo- fue secularizándose, con lo que el distanciamiento fue creciendo más aún.

A los ojos de muchos historiadores del cristianismo antiguo, los testimonios arqueológicos de las primeras comunidades han aparecido como meros objetos de arte, como consecuencia de esta disociación. Su interés puede situarse a medio camino entre una admiración reverencial y una posición de corte un tanto academicista que hacía de los materiales arqueológicos a la vez objetos sagrados y piezas de arte ${ }^{2}$.

Por su parte, los arqueólogos han llevado por su cuenta y riesgo la interpretación de la funcionalidad litúrgica de los monumentos que iban excavando. Generalmente, y salvo contadas excepciones, la utilización de los textos escritos, sobre todo litúrgicos, ha sido en la mayoría de los casos totalmente aleatoria y sin tener en cuenta la opinión de los especialistas en liturgia, patristica o legislación conciliar ${ }^{3}$.

${ }^{2}$ No podemos olvidar el peso que tuvo la periodización propuesta por Winckelmann en el transcurso del siglo xvill y el perjuicio regresivo en el periodo comprendido entre el arte romano y el arte románico.

${ }^{3}$ Entre los estudios de arqueologia cristiana que se han interesado por la interpretación de la funcionalidad litúrgica de los espacios tenemos que señalar: J. LASsuS, Sanctuaires Chrétiens de Syrie. Paris 1947; P. Lemerle, Philippes et la Macédoine Orientale a l'époque chrétienne et byzantine, Paris 1945. Estudios más particulares sobre las pastophoriae como el ya clásico de G. BABIC, Les chapelles annexes des Eglises Byzantines. Fonction liturgique et programmes iconographiques, Paris 1969, o el reciente trabajo de G. Descoevones, Die Pastophorien im syrobyzantinischen Osten. Eine Untersuchung zu architektur- und liturgiegeschichtlichen Problemen. Wiesbaden 1983. Hay que destacar también el estudio para Jerusalén de M. BEN-PECHAT. L'architecture baptismale de la Terre Sainte du IV au VII siécle. Etude historique, archéologique et liturgique, Paris X, Nanterre 1985. Resulta también muy interesante la reciente aportación de P. DONCEEL-VOUTE, Les pavements des églises byzantines de la Syrie et du Liban. Decor, archéologie et liturgie, Louvain-la-Neuve, 1988. El estudio sobre las basilicas dobles de J. P. SODINI - K. Kolokotsas, Aliki II: La basilique double, Paris 1984. Para Constantinopla contamos con la obra de T. F. MATHEWS, The Early churches of Constantinople: Architecture and Liturgy. Pennsylvania 1980. Para África contamos con los numerosos estudios de N. Duval, del que cabe destacar, Sbeitla et les églises africaines a deux absides. Recherches archéologiques sur la liturgie chrétienne en Afrique du Nord, Paris 1971-73; estudio complementado por el de Y. Duval, para el culto de los mártires, Loca Sanctorum Africae. Le culte des martyrs en Afrique du IV au VII 
Arquitectura cristiana y liturgia: reflexiones en torno a la interpretación...

Todavia tendriamos que hacer otras consideraciones sobre la evolución de la arqueologia cristiana que afectan directamente a la realización de nuestro trabajo. Por diversos motivos, entre los que cabe contar que surgió al amparo de los círculos eclesiásticos, la arqueología cristiana empezó a disociarse de los progresos conseguidos por la arqueologia clásica, quedándose considerablemente rezagada con respecto a ésta. El adelanto científico que supuso la aplicación de los métodos estratigráficos a la arqueología clásica y el estudio de los materiales cerámiccs no tuvo la misma acogida entre los arqueólogos del primitivo cristianismo ${ }^{4}$. La adopción de las nuevas metodologias cientificas por la arqueologia cristiana es un fenómeno muy reciente por no decir contemporáneo. Este hecho determina sobremanera el estudio evolutivo cronológico de las basilicas cristianas, por cuanto la mayoría de ellas han sido excavadas con una metodologia deficitaria, habiéndose perdido definitivamente los argumentos que hubieran podido permitir cualquier apreciación diacrónica en la evolución de esos primeros edificios de culto. Como se suele decir, el excavar es como ir arrancando las páginas de un libro que sólo puede leer el excavador. A pesar de la irreversibilidad del proceso, cabe recapacitar sobre la posibilidad de la re-excavación de monumentos exhumados de antiguo para agotar las posibilidades del yacimiento, o, cuando menos, obtener un buen alzado planimétrico acorde con las nuevas tecnologias.

Por muy desoladoras que puedan parecer estas apreciaciones, creemos responde a una valoración real ante la cual no podemos mostrarnos negligentes. A menudo una misma basílica presenta unas remodelaciones que parecen obedecer conscientemente a un cambio en los rituales litúrgicos. Si estos cambios y refacciones del espacio interior de las basilicas no han podido ser perfilados cronológicamente a través de la arqueologia; ¿cómo entonces podremos aplicarle un texto contemporáneo si desconocemos el momento en que se llevaron a cabo tales remodelaciones? Son planteamientos importantes que deben influir en el futuro de las nuevas generaciones de arqueólogos del antiguo cristianismo.

\footnotetext{
siecle. Roma 1982. Para Hispania tenemos que citar la obra de T. ULBERT, Früchristliche Basiliken mit Doppelapsiden aut der lberischen Halbinsel. Studien zur Architektur- und Liturgiegeschichte. Berlin 1978: o los estudios de L. CABALLERO, de los que cabe destacar La iglesia y el monasterio visigodo de Santa Maria de Melque (Toledo). Arqueología y Arquitectura. San Pedro de la Mata y Santa Comba de Bande. Madrid 1980. Y el reciente estudio de L. OLMO, "Arquitectura religiosa y organización liturgica en época visigoda. La basilica de Recopolis". AEA, 61 (1981), págs. 157-178.

"Cfr. P. TESTINI, "L'Archeologia Cristiana quale disciplina oggi?", Atti del $V$ Congresso Nazionale di Archeologia Cristiana. (settembre 1979). Viella-Roma 1982
} 
Por una simple intuicion podemos saber que la funcionalidad de los espacios sacros responden a necesidades de tipo litúrgico. Pero antes de seguir adelante en esta reflexión sobre arquitectura cristiana y liturgia querriamos establecer unas normas para la definición y distinción de los diferentes espacios que constituyen un complejo eclesiástico, por quebradiza que pueda resultar en ocasiones la fijación de cualquier tipo de reglas.

En primer lugar, hay que distinguir entre los espacios físicos y las actividades que en ellos se desarrollan, la funcionalidad que se les atribuye. Es corriente el confusionismo entre los arqueólogos al designar las diferentes partes de una iglesia utilizando indiscriminadamente términos puramente litúrgicos - - de uso del espacio físico- para indicar ambientes genuinamente arquitectónicos.

El "espacio arquitectónico" es el escenario fisico de la iglesia con sus distintas partes constitutivas: los pórticos, los pies de la basilica, las naves y el ábside. No siempre el emplazamiento del mobiliario litúrgico -que indica la utilización ritual de los ámbitos- es uniforme, sino que varía según las diferentes áreas geográficas del orbe cristiano en consonancia a unas tradiciones en los usos litúrgicos. Así, por ejemplo, no podemos llamar nunca presbyterium al ábside de una basilica - por muy corriente que sea la localización de este ambiente litúrgico en la cabecera de las iglesias de la región donde trabajemos- porque estamos designando con un concepto de funcionalidad litúrgica un espacio físico arquitectónico. El término presbyterium constituye un uso litúrgico parcial del ábside de las iglesias, ya que, cuando el ábside desempeña esta funcionalidad, incluye, además, la cathedra o trono episcopal. Cabe asimismo la posibilidad de que el altar se situe también dentro del ábside, con lo que tendriamos la ubicación de otro espacio litúrgico - el sanctuariumdentro del mismo espacio arquitectónico.

De todo esto se desprende ya el concepto del "espacio litúrgico", aunque resulta difícil establecer unas normas rígidas definitorias. En principio diremos que se considera espacio litúrgico al escenario donde se realizaban las celebraciones relacionadas con los sacramentos de la religión cristiana. De estos sacramentos, los más importantes que requieren la adecuación de un espacio ad hoc son la synaxis eucarística y el bautismo, cosa que afecta directamente a la arqueología cristiana, puesto que existe un mobiliario litúrgico característico -altares, canceles, pisci- 
nas bautismales, etc. - que indica la funcionalidad litúrgica de estos ambientes.

En general, podemos decir que el espacio litúrgico lo constituye la basílica en si con su sanctuarium y quadratum populi -como espacio reservado a la celebración de los misterios y ámbito reservado a los fieles- y el baptisterio, siempre individualizado del espacio litúrgico eucaristico.

Pero las cosas no resultan tan sencillas. Sabemos también de la utilización de estos espacios litúrgicos para actividades seculares. Un ejemplo muy elocuente es la celebración de concilios eclesiásticos en el interior de las iglesias, una ceremonia secular que, si tenía cabida en un espacio sacro, es porque se consideraba que la presidencia real de estas asambleas episcopales la ejercia Dios ${ }^{5}$. A pesar de ello, no podemos considerar la celebración de los concilios como una ceremonia litúrgica, en todo caso, una actividad paralitúrgica con claras connotaciones religiosas que se realizaba - aunque no siempre- en un espacio litúrgico por antonomasia como es la basílica.

Junto a la secularización de estos espacios litúrgicos, tenemos también el caso contrario, el de la sacralización de los espacios profanos. Existen numerosos ejemplos de este fenómeno, pero sólo citaremos algunos de ellos. Uno es el uso de los pórticos, claustros o plazas situadas ante las iglesias en la vigilia pascual durante la celebración solemne del lucernario en el que se enciende el cirio pascual, ritual de una extraordinaria antigüedad acompañado de un boato litúrgico muy solemne ${ }^{6}$. También en los pórticos de las iglesias se hacían algunos ceremoniales en relación con los competentes o candidatos al bautismo.

Otro ejemplo altamente ilustrativo de la sacralización de los espacios mundanos lo constituyen las procesiones, cuyo carácter litúrgico era aun más manifiesto en la antigüedad que las que conocemos hoy en dia al

Cfr. C. Gooor. "El escenario arquitectónico de la celebración de los concilios hispanovisigodos", presentando al Congreso en conmemoración del xIv Centenario del III Concilio de Toledo (589-1989) (en prensa).

${ }^{6}$ La ceremonia del lucernario tiene un origen hierosolimitano. Cfr. J. R. BERNAL, “LeCturas y oraciones en la Vigilia Pascual Hispanica", Hispania Sacra, 17, (1964), pags. 283347. También J. FONTAINE. "Poésie el liturgie. Sur la symbolique criptique des luminaires, de Prudence à Isidore de Seville", Etudes sur la poésie latine tardive d'Ausone à Prudence Recueil de Travaux. Paris 1980, págs. 184-212. 
haber arraigado en la idiosincrasia etnológica de los pueblos. En efecto, en las procesiones de la antigüedad tardia, del período paleobizantino y de época visigótica ef carácter litúrgico venía marcado por la presencia de cruces procesionales, los Evangelios y la Sagrada Eucaristia simbolizando la presencia real de Cristo, además de las reliquias de los mártires $^{7}$. Es un concepto religioso-litúrgico de raiz oriental conocido con el nombre de hetoimasia que cuajó rápidamente en el pars occidentis del Imperio. En Hispania contamos con un texto muy instructivo sobre las solemnidades procesionales en la ciudad de Mérida, las Vitas Sanctorum Patrum Emeritensium ${ }^{8}$.

Por último tendriamos que delimitar la significación de otro concepto, el del "espacio religioso" no litúrgico. Se trata de ambientes situados junto a las basilicas, formando parte del mismo complejo eclesiástico, pero utilizados para fines seculares. El ejemplo más clarificador que se nos ocurre es el del palacio episcopal cuya ubicación suele ser próxima a la catedral. Debemos considerar también otras dependencias - muchas veces yuxtapuestas a la misma iglesia - dedicadas a actividades profanas de la propia parroquia como almacenes, bodegas, etc. Otro ejemplo muy ilustrativo es la localizacićn próxima a la iglesia de salas de audiencia o recepción dedicadas a funciones judiciales como las desempeñadas por el obispo (episcopalis audientia), y que en los textos -como hemos demostrado recientemente se conoce con el nombre de secretarium ${ }^{9}$.

Todas estas actividades son de carácter religioso, pero no litúrgico, por lo que determinan la funcionalidad de un espacio claramente diferenciado del espacio litúrgico y que podemos definir como "espacio religioso».

Sabemos por el canon 5 del III Concilio de Braga del 675 que era costumbre llevar las reliquias de los mártires en procesión en un arca a espaldas de los diáconos, repro. bando la presunción de muchos obispos que se las colgaban del cuello: De damnata praesumptione quorundam episcoporum qui in festivitatibus martyrum ad ecclesiam procedentes appensis collo reliquiis ab albatis diaconibus in sellulis vehuntur, J. VIVES. Concilios visigóticos e hispano-romanos, Barcelona-Madrid, 1963, págs. 377-378.

* Las descripciones de las procesiones en las VSPE nos revelan la pompa y la mag. nificencia de los obispos, comparándolos al propio monarca, referiéndose a Masona dice Ita nimirum temporibus eius ditati sunt ut in diem sacratissimum paschae quum ad ecclesiam procederet, plurimi pueri clamides olosericas induentes coram eo quasi coram rege incederent et, quod his temporibus nullus poterat nullus praesumebat, huius indumentis amicti ante eum debito deferentes obsequium pergerent VSPE, (V. 3, 11-12) ed. J. GarviN. The Vitas sanctorum Patrum Emeritensium, Washington 1946, pág. 196. La hetoimasia supone la entronización de los Evangelios, bien sea sobre un trono vacio o sobre el mismo altar: cfr. O. Demus. Byzantine Mosaic decoration. Aspects of Monumental Art in Byzantium, New Rochelle-Nueva York 1976.

Supra, nota 5 
La construcción de las basílicas cristianas de los primeros siglos sigue unas pautas o patrones que responden a unas exigencias del culto, a unas necesidades litúrgicas. Una simple revisión de los catálogos de las iglesias excavadas muestra, sin embargo, la gran heterogeneidad existente en la distinta disposición de los espacios litúrgicos de estos edificios, heterogeneidad manifiesta no sólo en la evolución diacrónica de estas basilicas sino también entre las distintas áreas geográficas del orbe cristiano. La explicación a este fenómeno debe buscarse en las distintas tradiciones seguidas por cada comunidad.

En efecto, hablar de liturgia en relación con la arquitectura cristiana resulta del todo incorrecto. Es más propio el término tradiciones o usos litúrgicos, un plural mucho más acorde con la realidad variopinta que presentan los restos de los antiguos edificios de culto descubiertos hasta nuestros días.

Pero esta heterogeneidad en la disposición de los espacios litúrgicos de los restos arqueológicos y de la cual inferimos la existencia de distintas necesidades del culto en la diversas zonas geográficas -exigencias cambiantes también con el paso de los años- se hace muy dificil de reseguir a través de los textos escritos. La utilización arqueológica de los textos litúrgicos es una tarea muy delicada que requiere un conocimiento previo y una metodología de trabajo específica sobre la que vale la pena que nos detengamos.

La liturgia. en todas sus tradiciones, está constituida por tres elementos: esquemas de celebración, textos $u$ oraciones propiamente dichos y rúbricas. Por norma general, diremos que las comunidades de los primeros años de la era cristiana aun no habian establecido unos usos u ordines específicos. Las fórmulas litúrgicas fueron apareciendo y gestándose con la extensión misma del cristianismo, primero con rituales bastante sencillos que fueron enriqueciéndose con el paso del tiempo. Grosso modo podemos decir que la organización del rito de la misa que, a grandes rasgos, coincide en todas las tradiciones litúrgicas, es el único resto fósil de lo que debió ser el primer intento de sistematización litúrgica, como arquetipo o punto de partida del cual, en su evolución, fueron diversificándose las distintas familias litúrgicas ${ }^{10}$.

$10 \mathrm{~L}$. DUCHESNE, Les origines du cuite chretien. Etude sur la lifurgie latine avant Charlemagne. Paris 1898. T. KLAUSER, Petite historire de la liturgie occidentale, Paris 1956. M RIGUETTI, Historia de la Liturgia, Madrid 1955 
¿Qué tipo de información puede sustraer el arqueólogo de los textos litúrgicos? Evidentemente todos aquellos datos que hagan referencia a las circunstancias de lugar donde se realizaba el culto, bien sea por alusiones directas a las formas o distribuciones espaciales, bien sea por referencias indirectas sobre la disposición de los celebrantes y de los fieles que nos puedan llevar a inferir la estructura espacial del escenario donde tenian lugar las ceremonias.

De los tres elementos constitutivos de la liturgia, el que más se ajusta a estas necesidades, a esta perspectiva arqueológica, es el cuerpo de las rúbricas. Las rúbricas concretan el ceremonial externo que han de seguir los ministros del culto: los gestos, los desplazamientos y las procesiones, un guión más o menos completo con numerosas bases para hacernos una idea del cuadro escénico donde se desarrollaba el culto ${ }^{11}$.

Para la utilización del cuerpo de las rúbricas debemos hacer, sin embargo, un llamamiento a la prudencia. Este es el elemento de la liturgia más flexible y sujeto a cambios de los tres, por estar más a mano del oficiante, al toque personal de cada uno de ellos y a las modas. Es también el cuerpo de las rúbricas el más tardio, siendo normalmente escrito en el momento en que un rito litúrgico, surgiendo de la iglesia que lo habia creado, se imponia en otra iglesia por razones de orden político o eclesiástico. Esto quiere decir que podemos tener un texto de una antigüedad extraordinaria cuyas rúbricas - lo que realmente nos interesa a la hora de interpretar la funcionalidad espacial de los monumentoshayan ido renovándose en una adaptación a las nuevas costumbres y a los nuevos espacios dedicados al culto.

Los liturgistas admiten en general que los ordines más antiguos de todas las tradiciones litúrgicas son los correspondientes a las grandes solemnidades como Navidad, Epifanía, Pascua y Pentecostés, y, en particular aquellas que contemplan un oficio vespertino y nocturno, sobre todo, la vigilia pascual ${ }^{12}$. Este hecho tiene una explicación lógica: son festividades que solamente se celebran una vez al año, por lo que, ya desde el momento en que se inició la sistematización de sus ceremonias y formularios, se hizo inminente la necesidad de ponerlos por escrito en

M. S. Gros, "Utilització arqueologica de la litúrgia hispana. Possibilitats i limits", "I Reunio d'Arqueologia Cristiana Hispanica, (Montserrat, 1978). Barcelona 1982, pág. 147167

La vigilia pascual es un oficio nocturno de una gran antigüedad, sus lecturas contienen todo el contenido litúrgico-sacramental de la iconografia paleocristiana; cfr. A. G. MARTIMORT, "L' iconographie des catecombes et la catechése antique", Rivista di Archeologia Cristiana, 25, (1949), págs. 105-114. Cfr. también J. Bernal, artículo citado. 
libelli que eran entregados a los responsables de las parroquias. No solo la celebración anual de estas festividades llevó a la cristalización escrita de estos ordines, sino que la complejidad ritual de estas grandes ceremonias la hacia imprescindible. Este es el caso, por ejemplo, de la vigilia solemne de Pascua, en la que, además de celebrarse la resurrección de nuestro Señor Jesucristo, tenia lugar la admisión de nuevos miembros en la comunidad a través de los sacramentos de la iniciación cristiana: el bautismo, la confirmación y la primera comunión, todo ello acompañado de una gran solemnidad ritual ${ }^{13}$.

La evolución de los ordines litúrgicos es una evolución orgánica, crece y se desenvuelve sobre unos modelos preexistentes. Su elaboración se efectua a menudo con centones, pedazos o fragmentos de un lado y de otro que llevan a nuevas fórmulas, añadidos, etc. Su desarrollo es comparable al del derecho, donde, a un fondo antiguo legislativo, se van añadiendo nuevas normativas, adaptándose a las necesidades de cada época ${ }^{14}$. El resultado final es la suma de aportaciones diacrónicas que configuran el grueso del cuerpo legal. Para desgajar y poder datar esas leyes es necesario ser un especialista en el derecho de las diferentes épocas. De igual manera, para diferenciar la antigüedad de los rituales litúrgicos, se requiere una preparación en la materia, propia de los liturgistas.

Cabe tener en cuenta, además, que los vehículos de transmisión de las tradiciones litúrgicas antiguas son muy tardios, generalmente carolingios y medievales. Estos corpora - como ya hemos señalado- no diferencian las partes antiguas de las más modernas, sino que constituyen, en la mayoria de los casos, una recopilación de los libelli de las diferentes festividades, suprimiendo aquello que encontraban obsoleto y añadiendo lo necesario para obtener un ordo renovado que garantizara la validez en el momento en que se llevaba a cabo esta recompilación.

El lector se preguntará desconcertado: ¿cuáles son entonces los criterios para dilucidar la antigüedad de los ritos en unos textos litúrgicos contenidos en manuscritos medievales?

13 C. Godor, Baptisterios hispánicos: Arqueologia y Liturgia. Tesis de Licenciatura, Universidad de Barcelona, 1985. A. HAmman, El Bautismo y la Confirmación, Barcelona 1982.

${ }^{14}$ Para esta cuestión cfr. la obra indispensable de J. FontaINE, Isidore de Séville et la culture classique dans l'Espagne Wisigothique, Paris 1955; M. C. DIAZ Y DIAZ, "La cultura de la España Visigótica del siglo VIl”, V Sett. Stud. Alt. Medioev., Spoleto 1958, pág. 813844. 
Esta tarea - permitasenos la comparación- es comparable a la de una excavación arqueológica. Los estratos constituyen las diferentes aportaciones temporales a la configuración final —casi siempre medieval-- del ordo. Pero, a diferencia de la arqueología, la liturgia no cuenta con esos vestigios materiales bien sistematizados que permiten al buen excavador efectuar un estudio evolutivo del yacimiento en el que trabaja, sino que todos los elementos se hallan sobre el mismo plano.

La metodología de trabajo que proponemos -el único sistema que creemos sensato- para la datación de esos estratos antiguos de las tradiciones litúrgicas es la comparación con testimonios escritos bien fechados, bien sean de carácter patristico o de legislación conciliar. La única manera correcta y segura de datar los rituales contenidos en un manuscrito litúrgico es encontrar un texto de algún Padre de la Iglesia o de algún concilio que nos permita retrollevar la celebración de ese ritual -en un espacio litúrgico concreto- a los primeros siglos del cristianismo, contemporizando de esta manera los monumentos y los textos, la arquitectura y la liturgia ${ }^{15}$.

¿Hasta qué punto resulta válido este método de datación? Somos conscientes de que el sistema preserita sus ventajas y sus inconvenientes. Como ventaja más destacable cabe resaltar la absoluta seguridad que ofrece al compararlo con testimonios escritos bien fechados a la hora de reconstruir los arquetipos de las antiguas ceremonias liturgicas.

Frente a esto son, sin embargo, muchos los inconvenientes con los que nos encontramos. En primer lugar, habremos de tener en cuenta el factor del azar. Cabe la posibilidad de que un ritual contenido en un texto litúrgico medieval se realizara ya en época antigua, pero que, al no haber llamado la atención de ningún escritor antiguo ni haber sido causa de litigio en ninguna asamblea conciliar, sea muy difícil demostrar el arcaismo de este uso. Poco puede hacerse a este respecto desde un punto de vista estrictamente científico. Pero aquí puede entrar en juego la intuición, cosa que no tiene por qué ser necesariamente perjudicial. La constatación arqueológica, por ejemplo, de algunas instalaciones de espacios litúrgicos específicos para la realización de determinados rituales -de los cuales no tengamos prueba escrita alguna de su antigüedad- puede considerarse como argumento suficiente para demostrar la coetaneidad del rito con los restos monumentales, siempre y cuando éstos estén bien

15 Queremos agradecer desde aqui las enseñanzas que M. S. Gros nos ha ofrecido en la Facultad de Teologia de Barcelona para elaborar esta metodologia de trabajo con los textos litúrgicos y los monumentos. 
fechados arqueológicamente. De esta manera la arqueología puede, en este aspecto, auxiliar las diferencias de la liturgia, afianzando la interrelación interdisciplinar de dos ciencias que interrogan un mismo sujeto.

Tampoco puede olvidarse otro inconveniente importante de este procedimiento que proponemos - consecuencia también del azar-en esta reflexión sobre arquitectura cristiana y liturgia. ¿Realmente las tradiciones litúrgicas que se han preservado hasta nuestros dias hacen justicia a los particularismos de las distintas comunidades, de las que se nos han conservado, por contra, los restos de unas iglesias con una personalidad propia? Hay que tener en cuenta que, por motivos de política eclesiástica y de prestigio, muchos de los usos particulares de comunidades minoritarias, que desarrollaron en su tiempo una edilicia cultural propia, fueron engullidos por las grandes tradiciones litúrgicas. Los dos ejemplos típicos de imposición de usos litúrgicos son el de la liturgia bizantina y el de la liturgia romana ${ }^{16}$. A estas imposiciones sucede, como es lógico, la pérdida de las costumbres litúrgicas propias y anteriores, y, en algunos casos, la desaparición también de los libros que contemplaban estos ordines, o la mezcla de las dos tradiciones.

Este hecho es de una trascendental importancia para la arqueología por cuanto podemos encontrar zonas con iglesias que presenten unas caracteristicas específicas que permitan individualizarlas por grupos; pero, por el contrario, que no contemos con ningún testimonio escrito que nos lleve a la reconstrucción de esas antiguas costumbres rituales para la interpretación de esos ambientes litúrgicos. En todo caso el historiador sabrá como valorar estos argumentos ex silentio.

Por lo que se refiere a las rúbricas, son precisamente éstas las más susceptibles de contaminarse de estas tradiciones litúrgicas $y$, como quiera que son los elementos más útiles para la interpretación funcional de los restos arqueológicos --por ser prolijas en alusiones espaciales-, queremos reiterar de nuevo un llamamiento a la prudencia ${ }^{17}$.

Todas estas reflexiones y planteamientos no pueden quedarse al margen de ningún estudio que pretenda cotejar los restos monumentales de la antigua arquitectura cristiana con los testimonios escritos de las tradiciones litúrgicas.

${ }^{16}$ Para esta cuestión, cfr. las obras de L. DuCheSNe y T. KLAUSER, citadas.

Lógicamente las rúbricas, al describir el desarrollo fisico de las ceremonias, se adaptan rápidamente a los nuevos escenarios liturgicos y, por lo tanto, al espacio interno de la basilica. 
Vamos a realizar ahora un periplo por las antiguas tierras del imperio occidental, deteniéndonos en los pormenores de la adecuación de los diferentes ordines litúrgicos con los restos de las basílicas de cada una de sus provincias.

\section{TRADICIONES OCCIDENTALES}

\section{A) África}

El territorio que configuraba las antiguas provincias romanas de África del Norte ha obsequiado a la arqueologia con un extenso número de restos monumentales de diversas épocas: fénico-púnica, romana y también cristiana. La cantidad de complejos eclesiásticos exhumados en África del Norte supera con mucho el resto de las provincias eclesiásticas del occidente mediterráneo (alrededor de 300 basilicas, según cómputo reciente de Isabelle Guy ${ }^{18}$ ). Este hecho no debe interpretarse como simbolo de una extraordinaria riqueza de estas provincias africanas en comparación con el resto del territorio de la pars occidentis del Imperio, sino como fruto del azar que, en este caso, ha desafiado a los avatares del paso del tiempo.

También existe una explicación lógica a esta excepcional preservación de los restos arquitectónicos romanos y tardorromanos en África del Norte. La ocupación romana de estas provincias - cuya población era en su mayoria nómada - supuso la creación y transposición de una red urbana, inexistente hasta entonces, creando ciudades de nueva planta ${ }^{19}$. La llegada del Islam a estos territorios - también con una civilización urbana - conservó algunos de estos núcleos urbanos, pero la mayoria fueron abandonados y despoblados hasta nuestros dias. La ausencia de continuidad en la ocupación de esas ciudades ha favorecido que se conservaran casi intactas hasta hoy, sufriendo únicamente la degradación

${ }^{18}$ En su tesis doctoral defendida en la Sorbonne, (Paris IV), bajo la dirección de N. Duval, que publicará próximamente.

19 P. A. Fevrier, "Notes sur le développement urbain en Afrique du Nord Les exemples compares de Djemila et de Sétif", Cahiers Archéologiques, (1964), págs, 1-47. J. LASSUS, "Adaptation de l'Afrique à l'urbanisme romain". VIII Congrès International d'Archéologie Classique, París 1965, pág. 245-259. 
que cualquier monumento en ruinas padece al ser utilizado como cantera de piedras.

Por desgracia, este ingente número de monumentos favorece más los intereses de los ministerios de turismo de estos paises que a las necesidades de la ciencia arqueológica. En efecto, no podemos decir que en este caso la calidad del conocimiento arqueológico pueda equipararse a la cantidad.

La mayoria de las excavaciones de esta zona se efectuaron hace años, sin tener en cuenta las ventajas que ofrecen hoy en día las nuevas tecnologias aplicadas a una buena metodología arqueológica. Cabe destacar, sin embargo, la importancia del papel desempeñado por las misiones francesas e italianas en estas tierras que primero fueron colonias y luego protectorados ${ }^{20}$. A pesar de todo, hoy en día, se llevan a cabo buenas excavaciones en algunos yacimientos, entre los que cabe destacar - por su seriedad- la labor de la Universidad de Michigan en Cartago, por ejemplo ${ }^{21}$.

Todo esto nos presenta una realidad arqueológica bastante desoladora - por lo general y salvo algunas excepciones - en lo que concierne a la datación de la construcción y evolución de estas iglesias africanas. La decepción es tanto mayor cuánto la mayoría de estas basilicas presentan interesantes remodelaciones en sus espacios litúrgicos, cambios que en su mayor parte no han podido ser fechados científicamente. Algunos autores han puesto en relación esas reformas con la imposición de un nuevo rito litúrgico en estas provincias, imposición que han identificado con la llegada de los bizantinos en tiempos de Justiniano ${ }^{22}$. Se ha de ser extremadamente prudente, sobre todo, cuando no tenemos certeza alguna del momento en que se hicieron tales reformas y más aun cuando se desconocen las particularidades del rito bizantino-africano de mediados del siglo vı y se ignora casi por completo en qué consistian los ordines africanos anteriores al desembarco justinianeo.

\footnotetext{
Cabe destacar las intervenciones francesas en Tunez y Argelia y las italianas en Libia.

Los trabajos de excavación efectuados por la Universidad de Michigan en Cartago se ven complementados por la publicación de sus trabajos en una serie de monografias, entre el Institut d'Archeologie et d'Art tunecino, las American schools of Oriental Research y la propia Universidad de Michigan.

N. Duval, Sbeitla..., obra citada. La llegada de los bizantinos al norte de África fue una ocupación militar. El ejército debia acompanarse de capellanes castrenses y las basílicas construidas para seguir el rito bizantino debian ser contadisimas, como la del praesidium de Timgad.
} 
Si. este es el drama de las provincias africanas. Todo lo generoso que ha sido el destino en la conservación de sus monumentos ha sido parco en la preservación de sus tradiciones liturgicas. Primero la llegada de los vándalos, despues la de los bizantinos y finalmente la conquista arabe del África del Norte llevó a una extrema inestabilidad a la iglesia de estas provincias, con numerosas huidas y exilios, tanto de personajes ilustres, como de comunidades monásticas enteras. Sea por este motivo o por otros, el caso es que no se nos han conservado los libros litúrgicos de la tradición africana, quizás extraviados en tales huidas o finalmente diluidos entre los ordines de las provincias eclesiásticas vecinas ${ }^{23}$.

Tan solo nos ha llegado los restos muy fragmentarios de un salterio y fragmentos de un leccionario de la misa y de un antifonario - todos ya del siglo $1 x$ - que no resultan de gran utilidad para la interpretación de la funcionalidad de los espacios litúrgicos de las basílicas africanas ${ }^{24}$. Los únicos textos escritos que pueden servirnos para este propósito son las obras de los Padres de la Iglesia africana, entre los que cabe destacar a Tertuliano. Cipriano y San Agustin, teniendo en cuenta la distancia cronológica que separa sus testimonios para poder efectuar esa sincronización entre éstos y los monumentos. Contamos también con una colección importante de concilios eclesiásticos de estas provincias con abundantes referencias a los usos y espacios litúrgicos. Eso es todo.

\section{B) Galias}

La riqueza monumental de las Galias no puede equipararse ni con muchos a la de las tierras africanas, pero sin duda debió de ser de una importancia nada desdeñable a juzgar por la situación de la prefectura del pretorio en Arlés. A pesar de no ser muy numerosos los yacimientos de época paleocristiana, merovingia y franca, el vecino territorio francés cuenta con bastantes excavaciones urbanas de antiguos edificios de culto, cosa que la distingue de otras provincias occidentales ${ }^{25}$. Cabe des-

2 Leovigildo acogio a clerigos católicos africanos, como el abad Nanctus a quien proporciono tierras para que instalara su comunidad (VSPE, III, 2, ed. J. GARVIN, obra citada, pág. 156-157), o el abad Donatus que fundo el Monasterium Seruitanum entre el 560 y el 570 (ildefonso DE TOLEdo. Liber de Viris illustribus. IV. PL 96, col. 200).

24 Para la liturgia africana, cfr. K. GAMBER, Codices litugici latini antiquiores, Freiburg. 1968. págs. 29-55. W. C. Bishop, "The African Rite", Journal of Theologicai Studies, 13, (1911-12), pags. 250-277

${ }^{25}$ Destacan las ciudades de Arlés, Marsella. Lyon, Grenoble, Vienne, etc. 
tacar, en este sentido, la reciente publicación de un estudio realizado por un macroequipo sobre la topografía cristiana de las Galias en el que se ha realizado un esfuerzo por adecuar y complementar los restos arqueológicos con las fuentes escritas ${ }^{26}$.

Para lo que aqui nos interesa, de la interpretación de los espacios litúrgicos de las iglesias de las Galias, disponemos de documentación propia sobre el rito galicano, cuya peculiaridad requiere que nos detengamos un momento.

El rito galicano fue adquiriendo una personalidad propia desde los mismos albores del cristianismo. Sabemos, por Ireneo de Lyon, de la existencia de comunidades perfectamente organizadas a mediados del siglo II, en los que se ha podido rastrear una cierta influencia oriental ${ }^{27}$. Este influjo de las liturgias que se iban formando en el este del imperio no desapareció con el paso del tiempo, sino que, más bien al contrario, este contacto fue considerable durante finales del siglo $\mathrm{IV}$ y la primera mitad del siglo v. A partir del 450 estas relaciones con el otro extremo del Mediterráneo, precisamente durante el control vándalo del África del Norte - contrariamente a como siempre se habia creido-, se incrementaron notoriamente, empezándose a apagar a partir del primer decenio del siglo vi para acabar desapareciendo casi por completo con la ingerencia justinianea de la renouatio imperii en Occidente. A esta conclusión se ha llegado no sólo por el estudio de los contactos eclesiásticos, sino también por estudios en relación con el comercio y la cerámica, así como también por la investigación de la circulación monetaria ${ }^{28}$.

El conocimiento que tenemos de la liturgia galicana es, sin embargo, muy fragmentario. Su temprana erradicación como consecuencia de la política eclesiástica de Carlomagno y de Alcuino de York, y la imposición de la liturgia romana en torno al 800 provocó en unos casos su pérdida total y en otros un curioso sincretismo de usos litúrgicos que dio lugar al rito conocido con el nombre de "romano-franco" ${ }^{29}$. Este último rito puede

* La Topographie des cités de la Gaule des origines a la fin du VII siècle, Centre de Recherche sur l'Antiquité Tardive et le Moyen Age, Paris 1975-1986.

27 Cfr. P. F. BEATRICE, La lavanda dei piedi. Contributo alla storia delle antiche liturgie cristiane, Roma 1983

${ }^{28} \mathrm{Cfr}$. las contribuciones de J. M. Gurt-T. MARot, Models de circulació monetària a les Balears (Pollentia i Fornells: una qüestió arqueologica); F. TUSET. Les ceramiques fines de Fornells en el context de la Mediterrània Occidental; y C. GoDor, El sincretismo liturgico oriental en la Galia mediterránea durante los siglos v y vi, a la Ill Reunió d'Arqueologia Cristiana Hispánica (Mahón, septiembre de 1988), en prensa.

${ }^{29}$ L. DuChESNE. Origines du culte chrétien, obra citada, pág. 208 y sS. M. RigheTtI. 
presentar algunos ceremoniales arcaicos estratificados que, para poderlos datar con seguridad, no nos queda más remedio que recurrir a testimonios patrísticos o conciliares que permitan retrasar su datación, la cual, como hemos señalado, ha de considerarse hacia el 800.

Otro camino para poder individualizar esos usos antiguos que constituyen el rito galicano puede ser el conocer perfectamente la tradición romana -cosa que es posible, como veremos- en el momento de su imposición en las Galias en época carolingia. De esta manera, por comparación, puede excluirse todo lo romano y delimitar los usos especialmente arcaicos. Esta vía es, no obstante, un tanto peligrosa por cuanto pudieron existir rituales análogos en una y ớra provincia eclesiástica, en época tardorromana o franca, cosa que sólo podremos demostrar a través de la patrística y la legislación conciliar ${ }^{30}$.

En cuanto a los libros litúrgicos conservados del rito galicano contamos con los restos muy fragmentarios de un sacramentario, el conocido como Sacramentario de Munich, fechable, según los especialistas ca. el 650. Su parquedad en rúbricas hace que este manuscrito no nos sea de gran utilidad para la interpretación arqueológica de los espacios litúrgicos ${ }^{31}$.

Disponemos asimismo de dos misales del rito galicano el Missale Gallicanum Vetus y el Missale Gothicum y de un leccionario, el Leccionario de Luxeil. El Misal de Bobbio contiene una mezcla del rito galicanoromano y que puede ponerse en relación con la llegada de San Columbano y sus monjes al norte de Italia. Las rúbricas de estas fuentes litúrgicas deben fecharse con prudencia por comparación con textos bien fechados ${ }^{32}$.

Historia de la Liturgia, vol. I. Madrid 1955, págs. 137-160, A. A. KING, Liturgies anciennes, Paris 1961.

${ }^{30}$ L. DUCHESNE. obra citada, pág. 208 y ss.

" A. Dold-L. EIzENHOfER. Das Irische Palimsestsakramentar im CLM 14429 der Staatsbibliothek Munchen. Beuron 1964. Cfr. tambien las interesantes aportaciones de M. S. Gros. "Notes sobre les oracions "Post nomina recitata" i 'Collectio sequitur' del sacramentari gal lica CLM München 14429", Revista Catalana de Teologia, 9 (1984), pags. 103-115; y "Notes sobre les dues col-lectes "Post secreta" del sacramentari gal-lica München CLM 14429", Revista Catalana de Teologia, 10, (1985), págs. 369-376; y “El "Qui pridie" del sacramentari gal-lica München CLM 14429, Revista Catalana de Teología, 13 (1988), págs. 371-385.

32 K. Gamber. Codices Liturgici Latini Antiquiores, vol. I, Freiburg 1968, págs, 162-163. L. C. Mohtberg,. Missale Gallicanum Vetus, Roma, 1958. L. C. Mohlberg, Missale Gothicum, Roma 1961. E. A. Lowe. The Bobbio Missal. A Gallican Mass-Book (Ms. París. lat. 13246), Londres 1920. 
Otra obra que ha desafiado el paso de los siglos $-\mathrm{y}$ que no constituye un libro litúrgico, sino un tratado sobre liturgia galicana- es la Expositio Breuis Antiquae Liturgicae Gallicanae, la cual ha suscitado una fuerte polémica entre los estudiosos de la liturgia. Esta obra, atribuida al Pseudo Germain de París, se había considerado siempre del siglo vi. Los estudios de Wilmart despertaron una controversia no sólo en torno a la autoria de este prelado parisino del siglo vi, sino también sobre cuál fue la región galicana y el momento en el que se llevó a cabo este compendio. Quasten, por ejemplo, hace depender esta compilación de Hispania, apoyándose en las conclusiones obtenidas por Wilmart de que el autor de este tratado utilizó el De ecclesiasticis officciis de Isidoro de Sevilla -obra que vio la luz hacia el 620- por lo que habría que retardar la cronología de la Expositio a finales del siglo VII o principios del siglo $\mathrm{VIII}^{33}$.

El carácter descriptivo de la Expositio Breuis aporta una gran cantidad de detalles sobre los antiguos rituales y la ceremoniosidad de sus celebraciones en las iglesias. A pesar de esto, aconsejamos una gran prudencia en la utilización de este tratado, tanto más cuando los especialistas no se ponen de acuerdo ni en su lugar de origen ni en su datación.

Afortunadamente en las Galias se ha preservado una ingente colección de obras hagiográficas y patrísticas, producción literaria que las hace despuntar por encima de otras provincias eclesiásticas occidentales. Sin ánimo de entrar en detalles, mencionaremos la obra de Cesáreo de Arlés con una importante colección homiliética, entre otros escritos, que resultan altamente ilustrativos, no sólo para la ubicación topográfica de las iglesias de Arlés, sino también para la interpretación de los espacios litúrgicos ${ }^{34}$. Tampoco resulta desdeñable la obra de Gregorio de Tours, de mediados del siglo vi, muy rica en la descripción de los escenarios de

${ }^{33}$ Expositio Breuis Antiquae Liturgiae Gallicanae. El primero que editó este texto fue E. Martene, Thesaurus novus anecdotarum. V, Paris 1717, págs. 91-100. Migne copió esta edición en el volumen 72. cols. 83-98 de su Patrologia Latina. Otra edición crítica es la de J. Quasten, Expositio antiquae liturgiae Gallicanae Germano Parisiensi ascripta. Münster 1934. A. WILMART, "Germain de Paris (lettres atribuees a Saint)", DACL, VI 1, col. 1102. J. B. Thibaut, Lancienne liturgie gallicane, son origine et sa formation en Provence, Paris 1929, págs 23-75. J. QUASTEN, “Oriental influence in the Gallican Liturgy". Traditio, 1. (1943), págs. 55-78.

34 Para Cesáreo de Arles, G. Morin (ed.). Sancti Caesarii arelatensis opera varia. Epistulae. Concilia, Regulae monasticae. opuscula theologica, testamentum. Vita ab eius familiaribus conscripta, Maretioli 1942. G. MORIN (ed.). Sacti Caesari Arelatensis sermones, Corpus Christianorum, series latina, 103-104, Turnholt 1953. Cfr. también H. G. J. BECK, The Pastoral care of Souls in South-East France during the sixth Century, Roma 1950; y C. F. ARnOLD, Caesarius von Arelate und die gallische Kirche seiner Zeit, Leipzig 1894. 
las iglesias turonenses ${ }^{35}$. Igualmente útiles resultan los relatos hagiográficos de época merovingia y franca ${ }^{36}$.

Las Galias cuentan también con una importante legislación conciliar, una colección conciliar de sínodos eclesiásticos que se iniciaron en el 314 y mantienen una continuidad admirable hasta bien entrado el siglo vill ${ }^{37}$.

Patrística y legislación conciliar nos ofrecen unos datos seguros para la datación de algunos usos litúrgicos, puntos de referencia imprescindibles para reconstruir los ordines arcaicos de las antiguas liturgias galicanas.

\section{C) Milán}

Por lo que se refiere el caso milanés, debemos tener en cuenta, ante todo, la importancia política que desempeñó esta ciudad durante la segunda mitad del siglo IV. Milán fue la capital del Imperio y un bastión de la fe ortodoxa en Occidente frente a los avatares de la controversia entre arrianos y católicos que agitaron esta época postconstantiniana. Cabe destacar, en este sentido, la labor de San Ambrosio, prelado de la sede milanesa, quien jugó una influencia decisiva en el edicto que convirtió al catolicismo niceno en la religión oficial del estado romano, promulgado por Teodosio en el $380^{38}$.

La tradición atribuye a la brillante figura de San Ambrosio una gran actividad en la producción de obras de carácter litúrgico. En los tratados que se nos han conservado de este Padre de la Iglesia occidental se puede percibir el marcado carácter sacramental, al igual que la existencia

${ }^{35}$ Para Gregorio de Tours, cfr. Gregorii Episcopi Turonensis libri Historiarum X, Ed. B. KRUSCH, W. LEVISON, MGH. Scriptores rerum Merovingicarum, t. I, pars I, Hannnover 1951. Gregorii Episcopi Turonensis Miracula et opera minora, ed. B. KRusCH, MGH, Scriptores rerum Merovingicarum, t. I, pars II. Hannover 1959. Cfr. también la obra de L. PIETRI, La ville de Tours du IV au VI siècle, nafissance d'une cité chrétienne. Roma 1983.

${ }^{36}$ La vida de los santos cuenta con una buena edición de B. Kausch, Passiones vitaeque sanctorum aevi Merovingici, MGH, Scriptores rerum Merovingicarum, Hannover 1902, (reimpr. anást., 1977). Cfr. También B. Beck, Annotationes ad textus quosdam liturgicos et vitis Sanctorum aevi Merovingici Selectos, Roma 1939.

${ }^{37}$ Concilia Galliae, ed. C. Munier, Corpus Christianorum, series latina, 148 y 148 A, Turnholt 1963. Cfr. C. OE CLeRCQ, La législation religieuse tranque de Clovis a Charlemagne (507-814). Lovaina-París 1936.

38 G. Traversi, Architettura Paleocristiana Milanese, Milán 1964. 
de unos formularios y rituales bastante desarrollados. De hecho, la época de San Ambrosio es un período crucial en la cristalización de los ordines de la mayoria de las tradiciones occidentales, sin descartar, claro está, un desarrollo y enriquecimiento posteriores ${ }^{39}$.

La liturgia milanesa tuvo al parecer una identidad propia que la distinguía del resto de los usos occidentales. En tiempos de Ambrosio -como él mismo nos explica- en Milán se realizaban ritos muy diferentes que los que se practicaban en Roma, conscientemente, siguiendo su propia tradición ${ }^{40}$. Sin embargo, la influencia romana se dejó sentir muy pronto en los usos milaneses que fueron romanizándose poco a poco ${ }^{41}$.

Los compiladores medievales de los ordines arcaicos llamaban a esta tradición "liturgia ambrosiana", atribuyendo su codificación a San Ambrosio. Esto no quiere decir que la liturgia milanesa sea obligatoriamente obra de este santo, sino que estas atribuciones quizá se hicieron por motivos de prestigio.

En el siglo x la liturgia romana se impuso en Milán, principalmente en los esquemas de la celebración eucaristica ${ }^{42}$. De esta época datan precisamente las principales recopilaciones, pero hemos de contar que son versiones muy contaminadas ya por la tradición romana. En cualquier caso, la principal prueba del arcaismo de ciertos usos nos la ha de dar la patristica - principalmente las obras de San Ambrosio-, aunque hay que considerar que seguramente el destino ha hecho que se perdieran muchas de ellas o de otros autores contemporáneos. También cabe la posibilidad de analizar las tradiciones antiguas romanas bien dotadas para delimitar las prácticas arcaicas por comparación y, si aparecen, llegar a la conclusión de su ambivalencia para el rito milanés y el romano.

El libro litúrgico principal de la liturgia milanesa es el Beroldus sive ecclesiae Ambrosianae Mediolanensis Kalendarium et Ordines, editado

39 San Ambrosio cuenta con una ingente obra litúrgico-sacramental, cfr. B. BotTe, Ambroise de Milan: Des Sacraments, Des Mystères, C. 25 bis, Paris 1961

4o San Ambrosio advierte de la divergencia de costumbres entre Milán y Roma, refie. riéndose al rito del lavatorio de pies después del bautismo y reafirmándose también: "Deseo seguir en todo a la Iglesia romana - dice-, pero, con todo, nosotros también tenemos capacidad de discernir". San Ambrosio, La iniciación cristiana, trad. de C. BASEvi. Madrid 1977. págs. 70.71 .

4 Hacia el siglo v. con la retorma del Papa Gelasio, ha de datarse la primera romanización de la liturgia milanesa. La segunda romanización se fecha en torno al año 800 , ccn la reforma carolingia, una influencia de la liturgia de la Santa Sede que se difunde a través de la Iglesia carolingia.

42. A partir del siglo $x$, se abandonan los usos propios milaneses y se impone la liturgia romana por razones de prestigio y política eclesiástica. 
por M. Magistretti con manuscritos del siglo $\times 11^{43}$. Contamos también con una obra narrativo-histórica del siglo xI de Landulfus Senior (1070-1100) titulada Historia Mediolanensis, con abundantes referencias a las iglesias y las viejas costumbres litúrgicas de tipo histórico, hemos de pensar que seguramente Landulfus tuvo acceso a un tipo de documentación que no ha llegado hasta nuestros dias ${ }^{44}$.

Por lo que se refiere a las excavaciones arqueológicas en la sede de Milán y en el territorio de su diócesis, cabe destacar las realizadas en la catedral y su baptisterio, dirigidas por M. Mirabella Roberti, aunque el estudio completo del conjunto es aun fragmentario ${ }^{45}$. No menos meritorios son los trabajos de P. Testini cuyas intervenciones no se han limitado únicamente al territorio milanés ${ }^{46}$. Sin querer desmerecer el rigor cientifico con que se llevaron a cabo estas excavaciones, tenemos que decir que - siguiendo la tónica general propia de la arqueología cristiana a la que ya hemos aludido más arriba - pocas veces se tuvo en cuenta la datación de estos edificios siguiendo la secuencia estratigráfica de los materiales cerámicos.

Unas veces por falta de estos materiales y otras por el desconocimiento del rigor metodológico - la mayoría de estas excavaciones se efectuaron recién acabada la Segunda Guerra mundial-, el caso es que desconocemos a menudo la datación o la evolución cronológica de estas basilicas. Algunas veces incluso se han utilizado criterios de datación "por paralelismo", es decir, aplicándole la fecha de otro edificio con estructuras análogas, fechado con más o menos precisión científica. Este procedimiento de estudio evolutivo —del cual la arqueología cristiana ha hecho ciertamente un abuso- descuida en muchas ocasiones la proximidad o la lejanía geográfica y mucho menos llega a apreciaciones críticas sobre si un tipo de estructura litúrgica pudo o no imponerse coetáneamente en zonas bien distantes del orbe cristiano. De igual manera, este sistema no contempla, por norma general, las particularidades

${ }^{43}$ M. Magistrett, Beroldus sive ecclesiae Ambrosianae Mediolanensis Kalendarium et Ordines (saec. XII), Milán 1894 (reimpr. anást., Westmead 1968)

44 Landulfus Senior, Historia Mediolanensis, PL, 147, cols. 803-954.

45 M. Mirabela Roberti, "La Cattedrale antica di Milano e il suo Battistero", Arte Lombarda, 8, (1965), págs. 77-98; "ll battistero antico di Milano", VI CIAC, Roma 1965, págs. 706-707; “Edilizia e architettura ambrosiana a Milano», XXV Corso di Cultura sull' arte Ravennate e Bizantina, Ravena 1978, págs. 191-210.

46 P. Testini, aPaolino e le construzioni di Cimitile (Nola). Basiliche o tombe privile giate?" L'Inhumation privilegiée du IV au VIII siecle en Occident, (Créteil 1984), Paris 1986, págs. $213-220$ 
que, tanto en la edilicia como en los rituales litúrgicos, pudieron caracterizar a ciertas comunidades.

Por lo tanto, en el momento de cotejar los textos con los monumentos, deberán tenerse en cuenta estas apreciaciones críticas que pueden por lo menos darnos una idea del margen de error en el que podemos incurrir, al tiempo que nos harán tomar conciencia del tipo de datos con los que estamos trabajando.

\section{D) Roma}

En lo que respecta a la ciudad eterna, fue aqui precisamente donde la arqueología cristiana empezó a suscitar un cierto interés entre los círculos eclesiásticos, primero, y luego entre el resto de los especialistas.

La riqueza monumental de Roma, con sus fastuosos restos arqueológicos, habia sido desde siempre foco de admiración por la antigua capital del Imperio. El descubrimiento de las catacumbas dio a conocer al mundo, la historia del cristianismo de los primeros siglos, de la mano de De Rossi, quien contó con el apoyo y mecenazgo del Vaticano para llevar a cabo sus investigaciones ${ }^{47}$.

Pero la riqueza monumental de la Roma paleocristiana no se limitaba únicamente a sus cementerios subterráneos. Efectivamente, su capitalidad propició otrora que fuera objeto de un programa constructivo importante, favorecido directamente por la familia imperial de Constantino, programa edilicio que tuvo también otros centros como Constantinopla, -la Nova Roma- y Tierra Santa ${ }^{48}$.

La ingente cantidad de basílicas construidas, al parecer, bajo los auspicios de la familia imperial constantiniana suscitó el interés de arqueólogos e historiadores de la arquitectura como Bovini y Krautheimer. Este último realizó un corpus de las basilicas de Roma, la mayoría de las cuales fueron objeto de excavaciones antiguas ${ }^{49}$.

${ }^{47}$ G. B. DE Rossi, La Roma sotterranea cristiana, Roma 1864-1877; Inscriptiones christianae urbis Romae septimo saeculo antiquiores, Roma 1861-1888; Piante icnografique e prospettiche di Roma anteriori al secolo XVI. Roma 1879.

48 R. Krautheimer, Arquitectura Paleocristiana y Bizantina, Madrid 1981

49 R. Krautheimer y otros, Corpus Basilicarum Christianarurn Romae. Ciudad del Vaticano 1939 y ss. G. BoviNI, Edifici di culto d'età constantiniana a Roma, Bologna 1968. 
Otro importante acontecimiento en la vida de la arqueología cristiana de Roma fueron los trabajos de excavación efectuados en San Pedro del Vaticano. Los trabajos, directamente propiciados y sufragados por la curia papal - durante el pontificado de Pio XII-, fueron dirigidos por Monseñor Kirsch con el propósito de hallar los restos del martyrium de San Pedro, con una clara intencionalidad de propaganda política para la sede vaticana $^{\text {s0. }}$.

La investigación arqueológica tropieza con una gran dificultad en las iglesias romanas. En primer lugar hemos de tener en cuenta que, curiosamente, son centros de culto que han gozado de una continuidad extraordinaria hasta nuestros dias, realizándose en ellas las refacciones y remodelaciones pertinentes, claro está. Este hecho ha limitado muchisimo el estudio en extensión del yacimiento, paso absolutamente básico de la ciencia arqueológica. En segundo lugar, se trata de excavaciones antiguas que se efectuaron en un momento en el que se desconocia el rigor científico de la secuencia estratigráfica y del estudio de los materiales cerámicos.

La realidad arqueológica de la Roma tardorromana y paleocristiana es bastante desoladora. En lo que nos concierne, diremos que el estudio de los espacios litúrgicos de estas iglesias resulta muy dificultoso por cuanto no tenemos certeza alguna sobre la vigencia cronológica de estos ámbitos. A título de ejemplo, diremos que no existe ninguna evidencia arqueológica que permita asegurar que el transepto de la basílica de San Pedro del Vaticano sea contemporáneo a la construcción de su fábrica, con los problemas que conlleva el estudio sobre la funcionalidad litúrgica de este espacio en una época tan temprana ${ }^{51}$.

Los datos fragmentarios que la arqueología proporcionaba para el estudio de las primeras basilicas cristianas de Roma, fueron complementados por una fuente documental de primer orden: el Liber Pontificalis. Este texto es una historia de la vida y de la obra de los distintos papas que ocuparon la cathedra de San Pedro, en el que se hacen alusiones directas a las diferentes construcciones eclesiásticas, muy prolijas, sobre todo, para la edilicia constantiniana. Estas noticias del Liber Pontificalis

J. P. KIRSCH, E. JUNYENT y otros, La tumba de San Pedro y las catacumbas romanas, Madrid 1954.

3 J. P. KIRSCH, "ll transetto nella basilica paleocristiana". Scritti in onore di Bartolomeo Nogara. Ciudad del Vaticano 1937, pág. 205 y ss. R. KRAuTHEIMER, “ll transetto nella basilica paleocristriana», V CIAC, París 1957, pág. 283-290 
han sido ampliamente utilizadas por la mayoria de los estudiosos de las iglesias antiguas de Roma ${ }^{52}$.

El empleo del Liber Pontificalis requiere, sin embargo algunas matizaciones. En efecto, el texto empezó a redactarse hacia el 530 aproximadamente, por lo que podemos dividirlo en dos partes: una, anterior a esta fecha, de carácter histórico; y la otra, posterior a ella, que constituye una crónica de las actividades papales. Por lo que se refiere a esta última parte no presenta más problema que una crónica cualquiera, mientras que la parte histórica resulta ya más dificultosa, tanto más cuanto que se aleja en el tiempo al momento de su composición. La dificultad se incrementa en las noticias referentes a época constantiniana, no sólo por ser fruto de una memoria colectiva histórica -que siempre puede estar algo deformada - sino también por una tendenciosidad propagandistica de la Santa Sede que hacia de Constantino el primer emperador cristiano, benefactor a un tiempo del imperio cristiano y de Roma. Resulta obvio, por lo tanto, que los datos referentes a las construcciones de época de Constantino, contenidos en el Liber Pontificalis deben tratarse con mucha prudencia, al poder estar exagerados por la propensión politica de sus redactores. Éstas y otras apreciaciones criticas sobre este texto pueden encontrarse en la edición que hizo Monseñor Duchesne del Liber Pontificalis.

En cuanto a la liturgia romana, podemos decir que es una de las tradiciones sobre las que se tiene más conocimiento de su evolución diacrónica. Aparte de una obra que recoge las costumbres litúrgicas de las comunidades cristianas de inicios del siglo III, titulada La Tradición Apostólica de San Hipólito ${ }^{53}$, contamos con el resto de los ordines romanos estudiados, codificados y editados por Andrieu ${ }^{54}$.

La edición crítica de la liturgia romana de Andrieu presenta los ordines en su evolución cronológica, un estudio de una fiabilidad extraordinaria, por haber completado estos testimonios litúrgicos con datos bien fechados de caracter patrístico, legislativo conciliar o de las decretales papales. Entre los ordines romanos cabe diferenciar entre la liturgia pontifical -cuyas solemnidades suelen revestir una gran antigüedad-, propia de la ciudad de Roma, y los ordines creados con el fin de exportarlos a otras iglesias e incluso otras diócesis, en un momento en que la importancia política y religiosa de la Santa Sede se iba incrementando. Ya

\footnotetext{
52 L. DUCHESNE, Le Liber Pontificalis. Texte, introduction et commentaire. Paris 1886.

53 B. Botre, Hippolyte de Rome: La Tradition Apostolique. SC. 11 bis, París 1968.

s4 M. Andrieu, Les Ordines Romani du Haut Moyen Age, Lovaina 1948.
} 
hemos hecho referencia más arriba como la liturgia romana se impuso en época carolingia en las Galias o en Milán a mediados del siglo x.

Así es que contamos con una evolución diacrónica perfectamente estipulada de los diferentes rituales litúrgicos del uso romano que puede llevarnos a un estudio aproximativo de la funcionalidad de los espacios internos de las basilicas romanas. $Y$ decimos aproximativo porque, a pesar de que las fuentes escritas nos pueden ofrecer - en este caso- una absoluta certeza cronológica de la celebración de un ritual, la arqueología no permite asegurar una datación certera para el escenario donde se celebran estas solemnidades, de manera que se hagan contemporáneos texto y monumento.

\section{E) Hispania}

El panorama arqueológico de Hispania está bien provisto de complejos eclesiásticos de época paleocristiana y visigoda, aunque con una distribución muy desigual en el territorio peninsular e insular. Por ejemplo, Menorca cuenta con cinco basíiicas cristianas conocidas, mientras, en comparación, la enorme extensión que supone Andalucía cuenta apenas con media docena de monumentos. Esto no puede interpretarse como indice de la cristianización más o menos profunda entre unas provincias y otras, sino que más bien corresponde a un fenómeno aleatorio propio al mismo tiempo del destino que ha permitido la conservación de unos edificios determinados y de la desigual prospección arqueológica entre las diferentes regiones de la Península ${ }^{55}$.

Como había pasado en otros paises europeos, los primeros que se interesaron por los monumentos cristianos de España fueron estudiosos vinculados a la Iglesia. Figuras de la talla de Mossén Camprubi para Centcelles ${ }^{56}$, Mossén Aguiló para Mallorca ${ }^{57}$, Mossén Martí Camps para

s5 P. DE PALOL, "Demografía y arqueología hispánicas (siglos IV-VIII). Ensayo de cartografia", BSAA, 34-35, Valladolid 1968-69.

so F. CampruBi, "l mosaici della cupola di Centcelles, nella Spagna", RACrist., 19, Roma 1942

5) Mn. J. Aguiló dejó unos manuscritos con sus anotaciones sobre la excavación de la basilica de Son Pereto y Sa Carrotxa que ordenó J. Puig । CADAFALCH, "Basilica cristiana primitiva en el paratge de Son Peretó a Manacor", Anuari de I'Institut d'Estudis Catalans, 6 (1915-1920), Barcelona 1923, págs. 737-746. 
Menorca ${ }^{58}$; o las obras de síntesis de Iturgáiz sobre los baptisterios de Hispania ${ }^{59}$ y la de Iñiguez con su compendio de arqueología cristiana ${ }^{60}$, son las principales aportaciones de la Iglesia española al conocimiento de los antiguos restos arqueológicos paleocristianos y visigodos. Algunos de estos investigadores estuvieron vinculados directamente con los trabajos realizados por el Pontificio Istituto di Archeologia Cristiana de la Cittá del Vaticano, como E. Junyent -quien colaboró en las excavaciones de la basílica de San Pedro- o, más tarde, M. Sotomayor o A. Recio Verganzones, ambos profesores de iconografia cristiana ${ }^{61}$.

Otro gran impulso para la arqueologia cristiana hispánica fue el que inició el Instituto Arqueológico Alemán --y que en la actualidad sigue desarrollando-, después de la Guerra Civil española. El principal promotor fue $\mathrm{H}$. Schlunk cuya obra abarca tantos estudios de historia del arte como de arqueología - a veces con la colaboración de T. Hauschild-, con trabajos tan importantes como Marialba (León), San Giāo de Nazaré o el mismo monumento de Centcelles (Tarragona). Estos dos autores han publicado también un catálogo de los monumentos cristianos hispánicos —obra ya póstuma para $\mathrm{H}$. Schlunk - incluida en la serie Hispania Antiqua ${ }^{62}$.

Pero la labor del Instituto Arqueológico Alemán no acaba aqui. Cabe destacar la obra de otro investigador alemán, T. Ulbert, quien se ha dedicado al estudio de las basílicas hispánicas de ábsides contrapuestos ${ }^{63}$, con la revisión y re-excavación de algunos de estos yacimientos como Casa Herrera cerca de Mérida, Torre de Palma, etc., entre otros monumentos de la Lusitania, como la iglesia cruciforme de Valdecebadar cerca

"H F. MARTI CAMPS, "Estracto de la memoria sobre la basílica de Son Bou". Alocución pastoral en ocasión del hallazgo y excavaciones de los restos de una antigua basilica de Son Bou, Boletin Oficial del Obispado de Menorca, Ciudadela 1952.

${ }_{4}$ D. Iturgalz, Baptisterios paleocristianos de Hispania, Barcelona 1970.

w. F. INiguez, Sintesis de Arqueologia Cristiana, Madrid 1977. Id., "Algunos problemas de las viejas iglesias españolas". Cuadernos de Trabajo de la Escuela Española de Arte y Arqueologia en Roma, CSIC, Roma 1955

6? Supra. nota 50

6. H. SCHLuNk, "Die frühchristlichen Denkmäler aus dem Nord-Westen der Iberischen Halbinsel", Legio VII Gemina, León 1970, pág. 477-509; Id., "La Iglesia de San Gião, cerca de Nazaré. Contribución al estudio de las influencias de la liturgia en la arquitectura de las iglesias prerrománicas de la Peninsula Ibérica", Actas do /l Congresso Nacional de Arqueologia, Coimbra 1971, págs. 509-528; en colaboración con T. HauschILD. Die Denkmäler der frühchristlichen und westgotischen Zeit. Hispania Antiqua, Maguncia 1978.

${ }_{63}$ T. UtBERT. Fruhchristliche Basiliken mit Doppelapsiden auf del Iberischen Halbinsel, Berlin 1978. 
de Olivenza ${ }^{64}$. Después de la publicación de su obra, T. Ulbert ha dirigido su atención hacia Oriente, participando en la misión que el Instituto Arqueológico Alemán realiza en Sergiópolis (Rusafa, Siria).

En el momento actual, los programas de investigación dedicados a época paleocristiana y visigótica del Instituto Arqueológico Alemán están personificados en A. Arbeiter, quien - según noticias recientes- trabaja sobre las disposiciones litúrgicas de las tempranas iglesias hispánicas, programa paralelo al nuestro, por lo que esperamos establecer una estrecha colaboración con este investigador alemán ${ }^{65}$.

Sin embargo, si alguien merece llamarse pionero en la investigación de la arqueologia cristiana hispánica, éste es $\mathrm{P}$. de Palol. Ya desde su

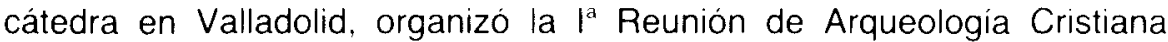
Hispánica en Vitoria en $1967^{66}$, congreso a nivel nacional previo a la organización del VIII Congreso Internacional de Arqueologia Cristiana que llevó a Barcelona en $1969^{67}$. Sus méritos le valieron para la creación de una cátedra de arqueología cristiana en 1970 - la única de toda la universidad española - que ha ocupado hasta hoy, y a la que sigue vinculado en categoría de emérito.

Desde la cátedra de arqueología cristiana de Barcelona, P. de Palol ha dirigido numerosos trabajos de excavación y revisión de los antiguos monumentos cristianos hispánicos. Cabe destacar el programa de las Islas Baleares en el que se incluyen las basilicas mallorquinas de Son Peretó y Sa Carrotxa; y las menorquinas de Es Cap des Port de Fornells, Son Bou, Es Fornás de Torelló y la llleta deł Rei. Por to que respecta a Cataluña, hay que señalar las excavaciones en la basilica y el poblado de época visigótica de El Bovalar (Serós, Lérida), o las llevadas a cabo en el castro visigótico de Puig Rom (Rosas, Gerona) ${ }^{68}$.

ix L. Caballero-T. Ulbefit. La basilica paleocristiana de Casa Herrera en las cercanias de Merida. Madrid 1976. T. Ulbert. "El Germo". Madrider Mitteilungen. 9. (1968), pag. 329. 398; Id. "Die westgotenzeitliche Kirche von Valdecebadar bei Olivenza (prov. Badajoz)". Madrider Metteilungen. 11, (1970)

${ }_{65}$ A. ARBEITER dicto una conferencia en Merida el dia 5 de diciembre de 1989 con el título de "Las disposiciones litúrgicas de las iglesias hispánicas paleocristianas y altomedievales".

sh $\mu$ Reunion de Arqueologia Paleocristiana Hispanica Vitoria 1967

6i VIII CIAC. (Barcelona, 1969). Barcelona-Ciudad de! Vaticano 1979

68 P. de Palol-G. Rossello-Bordor-A. Alomar-J. Camps. Nolas sobre las basilicas de Manacor, en Mallorca, Valladolid 1967. P. DE PALOL. "Catalunya i Balears en temps paleocristians i visigotics. Les noves descobertes arqueologiques i literàries". Memoria de l'institut d'Arqueologia i Prehistoria. Universidad de Barcelona, 1981, págs. 37-47; "La basilica des Cap des Port, de Fornells Menorca", I ${ }^{*}$ Reunio d'Arqueologia Paleocristiana Hispanica. (Montserrat, 1978), Barceiona 1982, págs. 353-404. R. PITA-P. DE PALOL, "La basilica de 
Pero una de las aportaciones más interesantes de $\mathrm{P}$. de Palol es su obra de sintesis, Arqueologica Cristiana de la España Romana, donde recoge todos los monumentos, a pesar de que muchos de ellos fueron excavados de antiguo. Su publicación en 1967 no le exime de seguir siendo de una validez extraordinaria ${ }^{69}$.

Quizá lo más meritorio de la cátedra de Barcelona para el desarrollo de la arqueologia cristiana hispánica haya sido elevar esta joven ciencia a las tribunas y reuniones internacionales, ganándose un puesto entre los más prestigiosos investigadores de la materia, con una continua participación en los congresos internacionales.

Cabe destacar también otra de las propuestas de la cátedra de BarceIona, a la cual nos sentimos directamente relacionados, formulada en la II $^{\mathrm{a}}$ Reunión de Arqueologia Cristiana Hispánica, celebrada en Montserrat en 1978. consistente en la colaboración interdisciplinar de las ciencias que tienen por objeto el cristianismo antiguo. Nuestra línea de investigación que coteja textos y monumentos surge de esta propuesta ${ }^{70}$.

Otro grupo dedicado a la arqueología de época visigótica, vinculado primero al Museo Arqueológico de Madrid, y más tarde al Consejo Superior de Investigaciones Científicas, es el representado por L. Caballero, quien ha realizado excavaciones en las iglesias de corte áulico, tradicionalmente llamadas visigóticas, además de efectuar colaboraciones con el Instituto Arqueológico Alemán, sobre todo, con T. Ubert en Casa Herrera. Hay que señalar los trabajos efectuados en Santa Maria de Melque (Toledo), Santa Lucia del Trampal en Alcuéscar (Cáceres) o El Gatillo "1.

No podemos olvidar las noticias concretas sobre yacimientos y los nuevos hallazgos que - como corresponde a una investigación activase van produciendo. Hay que destacar el reciente descubrimiento de la basilica de Ceuta $^{72}$, o la de Gerena en Sevilla ${ }^{73}$. Algunos de estos yaci-

Bobala y su mobiliario litúrgico". VIII CIAC, (Barcelona, 1969), Barcelona-Ciudad del Vaticano 1979. págs. 383-401.

69 P. DE PALOL. Arqueologia Cristiana de la España Romana (siglos iv al vi), MadridValladolid 1967

Obra citada. publicada en Barcelona 1982

L. Caballero-J. I. Latorre, La iglesia y el monasterio de Santa Maria de Melque (Toledo). Arqueologia y Arquitectura. San Pedro de la Mata (Toledo) y Santa Comba de Bande (Orense). Madrid 1980. L. Caballero, "Hacia una propuesta tipológica de los elementos de arquitectura de culto cristiano de epoca visigoda. Nuevas iglesias de El Gatillo y el Trampal". "l Congreso de Arqueologia Medieval Española. Madrid 1987.

"D. Bernal. "La basilica paleocristiana de Ceuta", Revista de Arqueologia, 101, septiembre de 1989.

${ }^{3}$ F. Fernandez Gomez-J. Alonso de la Sierra-M. Gracia, "La basilica y necrópolis 
mientos han sido objeto de la aplicación de las nuevas técnicas arqueológicas, con to que contamos con fechas fiables para algunos ambientes litúrgicos; citaremos la basílica del anfiteatro de Tarragona o la de la Almoina de Valencia ${ }^{74}$.

Estos restos arqueológicos, unas veces datados con más precisión científica, otras con menos, configuran los testimonios de lo que debieron ser los antiguos escenarios del culto cristiano hispánico. Estas iglesias surgieron como consecuencia de la cristianización de la Peninsula en época paleocristiana, pero su perduración llega a época visigótica, hasta la invasión musulmana, es decir, un marco cronológico que va desde el siglo IV al VIII. Con estos monumentos tendremos que cotejar los textos escritos que nos lleven a una interpretación de la funcionalidad litúrgica de los diferentes espacios de las iglesias hispánicas.

Por lo que se refiere a la tradición litúrgica de Hispania, su incorrecta atribución a la época mozárabe ha sido como una losa que durante mucho tiempo ha desviado la atención de los historiadores de la antigüedad. Estudios posteriores han demostrado que gran parte de este cuerpo litúrgico - llamado hasta entonces "mozárabe»- había sido recopilado en época visigótica. Por este motivo se decidió cambiar la denominación de "liturgia mozárabe" por la de «liturgia hispánica" ${ }^{75}$.

Aunque la aportación de época visigótica al corpus litúrgico es muy importante, hablar de «liturgia visigótica" tampoco es del todo propio. Hay que tener en cuenta, ante todo, que el pueblo godo profesaba la fe arriana, la cual habian adoptado tiempo atrás -en tierras de la Pannonia y el Ilyricum - bajo la instigación del obispo Ulfila. Con su llegada a las Galias, creando el reino de Tolosa, y su posterior asentamiento en la Peninsula, los godos ya llevaban su bagaje litúrgico y confesional que

paleocristianas de Gerena (Sevilla)", Noticiario Arqueologico Hispánico, 29, (1987), págs. 105-199.

${ }^{74}$ La basilica del Anfiteatro de Tarragona fue la contribución del TED'A a la III Reunió d'Arqueologia Cristiana Hispànica, (Mahón 1988), cuyas actas se hallan aún en prensa. En cuanto a la Almoina de Valencia, contamos ya con alguna publicación: J. BLASCO-V. ES Criva-A. Ribera-R. Soriano, "L'Almoina, centro arqueológico de Valencia", Revista de Arqueologia, 99, julio de 1989 ; Id. “Estat actual de la investigacio arqueologica de l'antiguitat tardana a la ciutat de València", comunicación presentada al mismo congreso de Mahón.

"S. J. PinelL, "Liturgia". Diccionario de Historia Eclesiástica de España, 2, Madrid 1972, págs. 1318-1320. J. M. DE MORA, "Bibliografia general, edición de textos, trabajos y repertorios", Estudios sobre la liturgia mozárabe, Toledo 1965, págs. 165-191. M. S. Gros, "Estado actual de los estudios sobre la liturgia hispánica". Phase, 16, (1976), págs. 227241. 
durante largos años constituyó un rasgo distintivo de la fides gothica frente a la fe romana propia de los ocupados ${ }^{76}$.

Desconocemos casi completamente la liturgia gótica arriana, siendo imposible establecer una comparación que permita reseguir cuál fue la aportación visigótica a la liturgia hispánica, si es que ésta llegó alguna vez a producirse ${ }^{77}$.

Resultó, sin embargo, de una capital importancia que el pueblo godo decidiera abrazar la fe católica, bajo el reinado de Recaredo en el 589, porque esto supuso -en el plano litúrgico- el triunfo de la tradición hispanorromana. Este vuelco del poder político hacia la romanidad es una de las razones por las que hoy podemos hablar de la época visigótica como una prolongación de la baja romanidad.

Por lo que aqui nos interesa, la conversión de los godos al catolicismo supuso una adopción oficial en todas las iglesias del reino de las formas litúrgicas hispanorromanas que estaban impregnadas de fórmulas tradicionales, cuyos origenes se han de buscar en época paleocristiana.

Todas las fórmulas litúrgicas -como en general todo el lenguaje religioso- tienen una tenaz perseverancia en sí mismas, respetándose siempre la tradición. Este espíitu se refleja también en la forma de componer las oraciones y plegarias litúrgicas: raramente se inventan nuevas expresiones, sino que - ateniéndose a unas normas rítmicas y unos cánones prefijados, según el tipo de oración deseada- se toman diferentes fórmulas tradicionales y se compone una nueva oración. Este método -que tiene más de compilativo que de compositivo- no permite la introducción de un lenguaje nuevo. A menudo se reconocen fragmentos más o menos extensos de homilías y tratados de los Santos Padres insertos en la liturgia. Es este espiritu de admiración hacia la santidad de la tradición, el que llevó a muchos autores a firmar sus tratados con el nombre de algún doctor de la Iglesia de reconocido prestigio, para que su obra tuviera mejor acogida ${ }^{78}$.

Así es que no podemos olvidar que la liturgia hispánica contiene un importante sustrato paleocristiano, aunque su compilación la fechemos en

76 C. Godor-J. VILELLA, "De la fides gothica a la ortodoxia nicena: inicio de la teologia politica visigótica", Los visigodos. Hisloria y Civilización, Murcia 1986, págs. 117-144.

Sobre este tema M. S. Gros prepara una ponencia al Symposium de la CNRS sobre los Visigodos y Europa que se celebrará en Mayo de 1990, titulada "Les Wisigoths et les liturgies Occidentales".

${ }_{78}$ C. Godor, "Notes històriques sobre les oracions "Post Vicesimam" de l'Oracional de Verona". Homenaje a Joan Maluquer de Motes (en prensa). 
época visigótica. La individualización de estos fondos antiguos resulta, sin embargo, bastante dificultosa. como veremos más adelante.

En lo concerniente al origen y formación de la tradición hispánica, diremos que, dentro del conjunto de las liturgias occidentales, la liturgia hispánica - a pesar de presentar sus puntos caracteristicos- se encuentra muy cerca de las liturgias galicanas y célticas. Este parentesco supone evidentemente un origen común que, de acuerdo con la opinión difundida ya a finales del siglo pasado por Duchesne y seguida actualmente por los mejores liturgistas como Gros. Pinell y Bellavista ${ }^{79}$, no puede ser otro que la sede de Milan. La semejanza de los esquemas de celebración, de las horas del oficio y de la organización del rito de Semana Santa apuntan hacia un arquetipo litúrgico que deberia formarse a mediados del siglo IV. En esta época, al adaptarse el catolicismo como religión oficial del estado romano, surgió la necesidad de precisar las normas de la disciplina eclesiástica y litúrgica; y, en Occidente, esta sede preminente era la ciudad de Milán que era, además, residencia imperial ${ }^{80}$.

El origen milanés del rito hispánico no excluye otras posibles influencias, no solo del resto de tradiciones occidentales - africana, galicana, romana-, sino también del resto de tradiciones orientales ${ }^{81}$. La aportación estrictamente hispánica se fecha entre el siglo VI y el VII, con diversos centros de creación: a finales del siglo vi, en la Bética y después, en el siglo VII, en la Tarraconense y la Cartaginense, con la figura de Julián de Toledo que marca el limite de la época de creación a la de recopilación ${ }^{82}$. Detectar esas líneas de parentesco es precisamente el objetivo de la investigación de los liturgistas y que se aparta considerablemente de nuestra lectura arqueológica de los textos litúrgicos.

La liturgia hispánica nos ha sido transmitida bajo la forma de dos tradiciones, la tradición A y la tradición B. A pesar de los cambios profun-

L. Duchesne. Origines du culte chretien, obra citada, págs. 93-99. J. M. Martin Patino. "El antifonario hispánico de Adviento. Contribución al estudio de sus fuentes", Miscelanea Comillas, 45, (1966), págs. 189-243. K. GamBER, "l piu antichi libri liturgici dell'alta Italia". Rivista di Storia della Chiesa in Italia. 15. (1961), págs. 71-81.

"M. S. Gros, "Utilització arqueologica de la liturgia hispana", articulo citado, págs. $153-155$

"A. BAumstaRk. "Orientalisches in altspanischer Liturgie", Oriens Christianus, 10, (1935). pág 3-37.

* El sucesor de Julián de Toledo. Félix, al inventariar la obra literaria de Julian, nos dice que hizo una nueva recensión del oracional festivo y del Liber Missarum que usaban en Toledo. Por to que dice, parece claro que Julián no creó nuevos libros, sino que los corrigió y completó. Cfr. M. C. DIAZ y DIAZ, "La techa de implantación del oracional festivo visigótico", Boletín Arqueológico de Tarragona, 113-120, (1971-1972), págs. 215-243. 
dos que supuso la desaparición del reino visigótico y la invasión islámica para el orden político peninsular, el proceso de difusión de los libros litúrgicos toledanos debió continuar después del 711, en la medida en que los arzobispos toledanos conservaron la jurisdicción sobre las iglesias del antiguo reino.

Por razones de orden práctico se ha convenido en llamar atradición $A$ " o "de los manuscritos" a todos los libros que concuerdan básicamente con los textos del Oracional de Verona; la "tradición B" O "de los libros impresos" los que siguen otra distribución. A la primera tradición pertenecen todos los manuscritos procedentes de los centros litúrgicos del norte de la Península y de la parroquia toledana de Santa Eulalia, mientras que los de la segunda tradición -de la que sólo se nos ha conservado dos manuscritos íntegros y dos fragmentarios- proceden de la parroquia de Santa Justa y Rufina de Toledo, y el misal y el breviario hispánicos codificados y publicados por orden del cardenal Cisneros, en los años 1500 y 1502, respectivamente.

Los estudios comparativos realizados hasta el momento demuestran que las dos tradiciones tienen leccionarios de la misa y colecciones de cánticos del oficio diferentes, asi como algunas divergencias en la estructura de las horas del oficio. En cambio ambas tradiciones siguen un mismo Liber Missarum que necesariamente ha de depender del ejemplar revisado por Julián de Toledo ${ }^{83}$.

Posiblemente, en los esquemas de celebración, la tradición B conserva algunos puntos más arcaicos que la $A$, pero se ha de tener mucha cautela a la hora de valorarlos. Mientras que en la tradición $A$ tenemos un texto tan antiguo como el oracional hispánico de Verona -datado hacia el 700- y puede ser reconstruida en el estado en que se encontraba a finales del siglo XI, cuando fue suprimida, la tradición $B$ persistió más o menos viva hasta su codificación en época de Cisneros, y seguramente se vio sometida a un proceso de fuerte romanización muy intenso a lo largo de los siglos XII-XV, cuando tuvo que coexistir con los ritos romano-francos impuestos por Bernardo de Sahagún en la mayoria de las iglesias toledanas ${ }^{84}$.

${ }^{83}$ Para la bibliografia concerniente a las dos tradiciones, cfr. M. S. Gros, "Estado actual", citado, págs. 237-238. Cfr. también R. PAstor DE TOGNERI, Conflictos sociales y estancamiento económico en la España medieval, Barcelona 1973, págs. 199-269.

84 J. F. Rivera Recio, La Iglesia de Toledo en el siglo XII (1086-1208), Roma 1966 , págs. 87-90. La primera noticia que tenemos sobre la presencia de clérigos mozárabes en las iglesias toledanas, después de la ocupación cristiana de la ciudad, es la carta de Eugenio III $-P L$ 180, col. 1559 que recoge las quejas del arzobispo Ramón de que los 
De los libros litúrgicos de la tradición hispánica, los que resultan más útiles son aquellos que contienen más rúbricas, con alusiones directas al espacio y al desarrollo de las ceremonias. En primer lugar hay que senalar el antifonario de la Catedral de León, que constituye una joya de la liturgia hispanica, puesto que se conserva prácticamente integro y se fecha en la primera mitad del siglo $x{ }^{85}$. Contiene algunas rúbricas en el rito de consagración de las iglesias y de ordenación de obispos, y los ordines que lleva insertos en los tiempos de Cuaresma y Semana Santa.

En segundo lugar, hay que contar con el libro que recoge los ordines de la celebración de las ceremonias del rito hispánico, el Liber Ordinum ${ }^{86}$. Sus numerosas rúbricas, en algunos casos muy detalladas, sobre todo en las ceremonias que sólo se celebran una vez al año - como la ordenación de ministros sagrados o las ceremonias de Semana Santa-, son de una importancia extraordinaria para la interpretación litúrgica de los espacios religiosos.

Sin embargo tenemos que ser extremadamente prudentes en la utilización de estas rúbricas litúrgicas. Es muy posible que, tanto el Antifonario de León como el Liber Ordinum, respondan a una adaptación realizada para las iglesias de Oviedo, capital del reino astúr-leonés, más que las toledanas. Según cuenta la Crónica Albeldense, Alfonso II el Casto (789-842) instauró el antiguo ceremonial de los visigodos, tal y como se desarrollaba en Toledo, en la iglesia y el palacio real de Oviedo ${ }^{87}$.

Teniendo en cuenta estas perduraciones de la liturgia hispánica y, ante la posibilidad de haberse impregnado de un lenguaje espacial que corresponda más a un tipo de arquitectura astúr-leonesa que a la arquitectura paieocristiana y visigótica, la utilización arqueológica de estas rúbricas debe extremar aun más la prudencia.

Efectivamente sólo podremos asegurar la antigüedad de este lenguaje referente al espacio si podemos demostrarla comparándola con

\footnotetext{
mozarabes no quieren acogerse a su autoridad. Esto permite suponer que el rito hispano fue suprimido por Bernardo de Sahagún y restaurado en las iglesias de Toledo por los mozárabes refugiados en la ciudad, a mediados del siglo XII.

${ }^{85} \mathrm{~L}$. Brou y J. Vives. Antifonario visigótico de la catedral de Leon. Texto notas e indices. Barcelona-Madrid 1959.

$\$ \mathrm{M}$. Ferotin. Le "Liber Ordinum" en usage dans l'Eglise Wisigothique et mozarabe d'Espagne du cinquième au onzieme siecle. Paris 1904.

8: A. C. Floriano, Diplomática española del periodo astur (718-910). Oviedo 1951. Cfr. tambien M. S. Gros. "El "Ordo Missae" de la tradición hispanica A". Liturgia y Música Mozarabes. Toledo 1978, págs. 50-60
} 
testimonios escritos bien fechados como la legislación conciliar a los textos literarios de los Padres hispánicos. Una vez seguros de que los datos para la interpretación del espacio liturgico pueden retrotraerse hasta época paleocristiana y visigótica, podremos aplicarlos sobre los monumentos hispánicos contemporáneos, de los siglos IV al VIII ${ }^{88}$.

*a legislación canónica hispánica esta muy bien editada y tradurida por J. VIVES, Concilios visigóticos e hispanorromanos, Barcelona-Madrid 1963. Cfr. también la obra de R. PUERTAS TRICAS quien ha recogido los textos escritos hispánicos referentes a la arquitectura religiosa: "Terminologia arqueológica en los concilios hispanorromanos y visigodos", I Reunión Nacional de Arqueologia Paleocristiana. Vitoria 1967, págs. 185-199; y su tesis doctoral, Iglesias hispanicas (siglos IV al VIII). Testimonios literarios, Madrid 1975. 